\title{
Dermatology: Future Therapeutic Perspectives
}

Richard B. Warren · Alan Menter

To view enhanced content go to www.dermtherapy-open.com

Received: November 18, 2013 / Published online: December 3, 2013

(c) The Author(s) 2013. This article is published with open access at Springerlink.com

With the ever increasing premiums placed on novel therapies that arrive to market, it is no surprise that many countries cannot afford to approve such medicines whilst others place stringent restrictions on their use. Furthermore, most medicines are rarely successful in all those individuals for whom they are prescribed, with $60 \%$ of patients on average initially deriving benefit [1]. Likewise, in the longer term many patients lose the initial benefit gained with the trigger factors responsible for these "flares" largely unknown. In addition to the unpredictability of adverse events, it is no surprise that for several decades

R. B. Warren $(\bowtie)$

The Dermatology Centre, Salford Royal NHS Foundation Trust, University of Manchester, Manchester Academic Health Science Centre, Manchester M6 8HD, UK

e-mail: richard.warren@manchester.ac.uk

A. Menter

Baylor Research Institute, Dallas, TX, USA

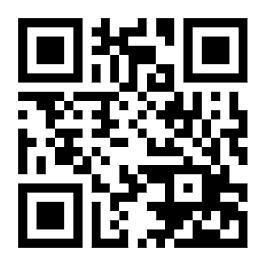

Enhanced content for this article is available on the journal web site: www.dermtherapy-open.com research efforts have been made to try and stratify therapies towards individuals and populations they would truly benefit $[2,3]$. In the last several years, the treatments of numerous cancers have been revolutionised by molecular diagnostics. A classic example in dermatology has been the discovery of the BRAF mutation which occurs in approximately $50 \%$ of individuals with advanced malignant melanoma. Those who express this mutation will often have significant initial responses to BRAF inhibitors. The longer-term benefits still remain to be fully understood but are improved by combined therapeutic approaches [4]. Cancers are accessible to such stratification as mutations in cancer cells are frequent, can be detected and then directly targeted. The situation for inflammatory skin diseases is more complex. For example, psoriasis as the archetypal inflammatory dermatosis, is a complex, multifactorial disease with interplay between genetics and the environment. Nonetheless, expensive biologic therapies are now routinely prescribed in many parts of the world for treating moderate-severe psoriasis. Predicting response to these drugs in individual patients is complex, such that stratification 
would be ideal to save money and unnecessary drug exposure. A recent example in an inflammatory condition, asthma, offers hope that stratification may be possible. Thus, it was demonstrated that a clinically relevant biomarker (periostin) was associated with the immunological pathway targeted by a specific therapy (anti interleukin-13) [5]. In dermatology, the target organ skin is accessible and utilising new technologies to study RNA transcripts expressed in psoriasis at early stages of therapy may allow replication of the findings in asthma. Further, bioinformatic methods to allow integration of the large datasets produced when studying "omics" are now well placed to facilitate the interpretation of these data and hopefully allow successful stratification of biologic therapies [6].

Finally, from a cost perspective, the recent approval by the European Medicines Agency (EMA) of 2 biosimilar agents to infliximab has opened up a whole new world of potential cost containment drugs with many of our biologic agents used in psoriasis, as well as in rheumatology and gastroenterology likely to lose patent protection over the ensuing 36 months. Rigid and expensive manufacturing procedures and the appropriate monitoring of "biosimilarity" by agencies such as EMA \& Food and Drug Administration are likely to restrict the number of companies having the capabilities to bring these less expensive biosimilar agents to market, to the current pharmaceutical companies manufacturing and marketing biologic agents [7].

\section{CONFLICT OF INTEREST}

AM has been a consultant, investigator, speaker, advisory board, and/or received grants or honoraria from the following companies: Abbott, Allergan, Amgen, Celgene, Eli Lilly, Galderma, Janssen, LEO Pharma, Novartis, Novo Nordisk, Pfizer, Stiefel, Syntrix Biosystems, Wyeth.

RBW has acted as a consultant and/or speaker for Abbvie, Amgen, Janssen, Lilly, Novartis, and Pfizer, all of whom manufacture biological therapies.

Open Access. This article is distributed under the terms of the Creative Commons Attribution Noncommercial License which permits any noncommercial use, distribution, and reproduction in any medium, provided the original author(s) and the source are credited.

\section{REFERENCES}

1. Pirmohamed $M$, et al. Adverse drug reactions as cause of admission to hospital: prospective analysis of 18 820 patients. BMJ. 2004;329(7456):15-9.

2. Ryan C, et al. The latest advances in pharmacogenetics and pharmacogenomics in the treatment of psoriasis. Mol Diagn Ther. 2010;14(2):81-93.

3. Warren RB, et al. The potential of pharmacogenetics in optimizing the use of methotrexate for psoriasis. Br J Dermatol. 2005;153(5):869-73.

4. Flaherty KT, METRIC Study Group, et al. Improved survival with MEK inhibition in BRAF-mutated melanoma. N Engl J Med. 2012;367(2):107-14.

5. Corren J, et al. Lebrikizumab treatment in adults with asthma. N Engl J Med. 2011;365:1088.

6. Warren $\mathrm{RB}$, et al. The future of biological therapies. Semin Cutan Med Surg. 2010;29(1):63-6.

7. Strober BE, et al. Biopharmaceuticals and biosimilars in psoriasis: what the dermatologist needs to know. J Am Acad Dermatol. 2012;66(2):317-22. 